\title{
Combination of mifepristone and misopristol in early fetal demise
}

\section{Atmajit Singh Dhillon, Karminder Kaur Dhillon*}

Department of Obstetrics and Gynecology, Command Hospital, Lucknow, Uttar Pradesh, India

Received: 14 March 2018

Accepted: 21 April 2018

\section{*Correspondence:}

Dr. Karminder Kaur Dhillon,

E-mail: bugidhillon6@gmail.com

Copyright: (c) the author(s), publisher and licensee Medip Academy. This is an open-access article distributed under the terms of the Creative Commons Attribution Non-Commercial License, which permits unrestricted non-commercial use, distribution, and reproduction in any medium, provided the original work is properly cited.

\begin{abstract}
Background: Generally misopristol alone is used in cases of early fetal demise successfully. However to further enhance the success rate a combination of mifepristone along with misopristol can be used. This results in avoiding anesthesia, surgery and operating theater resources, thus being economically viable and results in an overall greater patient satisfaction levels also. Globally, there is a general trend to grant patient greater autonomy in their treatment plan, minimize intervention levels, shorter hospital stay and quicker return to normal schedule and enhanced patient satisfaction levels.

Methods: 100 patients with early fetal demise, who reported to a tertiary care service hospital were prospectively evaluated. An oral dose of mifepristone $200 \mathrm{mg}$ stat and 48 hours later misoprostol $800 \mu \mathrm{g}$ was inserted vaginally. Three hours following the first dose, two further doses of $400 \mu \mathrm{g}$ misoprostol, was administered vaginally at 3 hours intervals. Repeat medical regime was offered with misoprostol patients who failed to pass products of conception. Success was defined as complete uterine evacuation within 3 days, without the need for surgical evacuation.

Results: The overall success rate of medical management was $84 \%$. Mifepristone alone induced natural expulsion of products of conception in (40\%) patients complained of heavy bleeding within 48 hours of mifepristone administration alone and in 29 (29\%) patients complete miscarriage was confirmed on ultrasound scan. Of the 68 women who were symptomatic at presentation the medical regime failed in $28(41 \%)$, compared with five (16\%) failures of the 32 who were asymptomatic. Of the 25 women who had surgical evacuation, eight required an emergency curettage for bleeding.

Conclusions: Combination of oral mifepristone along with vaginal misopristol is a simple, safe and effective means of treating early fetal demise, and is an effective alternative method to expectant and surgical options.
\end{abstract}

Keywords: Mifepristone, Misopristol, Missed abortion

\section{INTRODUCTION}

The management of early pregnancy failure has hinged on either, expectant, medical or surgical treatment. Majority of women used to undergo surgical evacuation for early pregnancy failure. Surgical management is the treatment option with ensures complete success, though patients have to undergo the anxiety of a surgical procedure and feel the lack of control in the treatment plan and is associated with the risks of anesthesia and surgery, hospitalization as well as greater requirement of analgesia and lesser degree of overall patient satisfaction levels. ${ }^{1} \quad$ Surgical option has significant financial implications as well. ${ }^{2}$ Some patients will choose surgical evacuation of retained products of conception because the treatment process is completed quickly and they can grieve and move on with their lives. Patients who choose expectant management, feel more empowered and in control, though with uncertain treatment time, no definite guarantee of completion and resulting in a possible prolongation of anxiety and distress. Expectant management has a low success rate, and is suitable for 
patients who are not convinced about the diagnosis and want a repeat scan later or are undecided about the definitive treatment option and want to wait for some time. ${ }^{3}$ Medical management is a viable option and there are various medical regimes have been described with a success rate of 25-92\%, depending on the type of miscarriage, outcome measures used, the dose, duration and route of prostaglandin administration. ${ }^{4}$ The flip side is that there will be a time lag for the process to complete and ultimately surgery may be required and that too as a emergency procedure.Besides patients have to be carefuly selected for the medical treatment and should be staying near to medical services and communication devices and transport should be readily available. Medical management helps patients feeling in control of their treatment plan and also contributes to judicious use of resources. $^{5}$

\section{METHODS}

100 patients with early fetal demise, who reported to a tertiary care service hospital were prospectively evaluated. Age bracket was from 9 years to 45 years, between 6 and 13 weeks of gestation, over a period of one year in a tertiary care service hospital. The assessment of gestational age was based on menstrual history, and all ultrasound measurements (crown-rump length, gestational sac diameter) were within the first trimester. The diagnosis of early fetal demise was confirmed on ultrasound by the absence of a fetal heart pulsation when the crown-rump length was $>7 \mathrm{~mm}$ and of an anembryonic pregnancy by absent fetal pole in a gestational sac $>25 \mathrm{~mm}$ in diameter. Successful treatment was defined as complete uterine evacuation using medical regimen without the need for surgical intervention. All patients with a miscarriage were counselled appropriately, and were offered a choice of medical or surgical treatment. Patients who opted for medical management received a single oral dose of 200 $\mathrm{mg}$ of mifepristone in hospital. Unless miscarriage occurred following administration of mifepristone alone, which was confirmed by ultrasound scan on patients who gave a history of heavy bleeding prior to misoprostol administration, women were admitted to the hospital 36$48 \mathrm{~h}$ later. On admission, four tablets (a total of $800 \mu \mathrm{g}$ ) of misoprostol were inserted into the posterior vaginal fornix by a nurse or by the patient herself. Following administration of the first dose, a further two doses of misoprostol (two tablets each) $400 \mu \mathrm{g}$ were given vaginally every 3 hours. If bleeding was heavy misoprostol was administered orally. If products of conception were passed they were sent for histopathological confirmation. Following misoprostol administration pulse, blood pressure, temperature and systemic symptoms were monitored hourly. Oral (paracetamol $500 \mathrm{mg}$ plus dihydrocodeine $10 \mathrm{mg}$ ) or parenteral analgesia (pethidine $25 \mathrm{mg}$ ) was administered as required. Patients who failed to pass products of conception had an option for further medical management with misopristol or surgical evacuation.
Complete uterine evacuation was confirmed clinically by observing expelled products of conception, speculum examination and ultrasound scan was performed to confirm the complete evacuation of the products of conception. Patients were called for review after two weeks or as required earlier for evaluation.

\section{Inclusion criteria}

- Ultrasound examination demonstrating:

1. Evidence of fetal demise (no fetal cardiac activity despite recognizable embryo and dates consistent with the likelihood of visible pregnancy) OR

2. Empty gestational sac with no evidence of incomplete abortion or growth over a 7-day period confirmed by two ultrasounds performed one week apart.

- If fetus exists, fetal size less than 12 weeks+6 days

- Closed cervical OS.

\section{Exclusion criteria}

- Active bleeding at enrollment and/or history of bleeding within the prior week.

- Allergies or other contraindications to the use of mifepristone or misoprostol.

- Suspected ectopic pregnancy.

- History of trophoblastic disease.

- Coagulation disorder and/or currently taking anticoagulants.

- Any serious medical condition.

\section{RESULTS}

The age of the 100 patients ranged from $19-45$ years. Of the 100 women, $67(67 \%)$ were primiparous and 33 $(33 \%)$ had one or more previous pregnancies. The mean gestation, by best estimate at the time of mifepristone administration, was $10.1 \pm 1.84$ weeks of amenorrhoea (range 6-13 weeks). At the time of the hospital visit, 34 (34\%) had vaginal bleeding, five $(5 \%)$ had pain and 20 $(20 \%)$ had both pain and bleeding. Thirty six $(36 \%)$ women were asymptomatic and the diagnosis was made at the routine first visit scans. Of the 100 patients, 40 (40\%) patients complained of heavy bleeding within 48 hours of mifepristone administration alone and in 29 patients $(29 \%)$ complete miscarriage was confirmed on ultrasound scan. Four (10\%) patients had emergency suction evacuation for heavy bleeding.

Total of 29 patients required surgical management for various reasons summarized in Table 1.

Among the 78 patients who were administered misoprostol, complete miscarriage occurred in 55 (70\%) patients (without the need for surgical intervention). Thus, the overall success rate was $(84 \%)$. Four women had emergency curettage for bleeding, two before and 
two after misoprostol administration. A total of five women had a blood loss $>500 \mathrm{ml}$ but none required a blood transfusion. Patients who had a successful outcome, complete uterine evacuation was confirmed ultrasonically. The average misoprostol dose required was three $(800+400+400 \mu \mathrm{g})$. Misoprostol to surgical intervention interval is as shown in Table 2.

Table 1: Indications for surgical intervention.

\begin{tabular}{|ll|}
\hline Indications & Total number (\%) \\
\hline $\begin{array}{l}\text { Emergency curettage for } \\
\text { bleeding }\end{array}$ & $8(28)$ \\
\hline Incomplete miscarriage & $14(48.2)$ \\
\hline No products passed & $4(14)$ \\
\hline Patient choice & $2(7)$ \\
\hline Molar pregnancy & $1(3.4)$ \\
\hline Total & $29(29)$ \\
\hline
\end{tabular}

Table 2: Misoprostol to surgical intervention interval.

\begin{tabular}{|l|l|}
\hline Before misoprostol & 4 \\
\hline Up to 3 days & 10 \\
\hline $4-14$ days & 5 \\
\hline$\geq 15$ days & 0 \\
\hline
\end{tabular}

The induction-miscarriage interval $50(50.0 \%)$ miscarried within 12 hours of receiving first dose of misoprostol. The average induction-miscarriage interval 12 hours and 8 hours in primigravida and multigravida patients respectively. The median duration of bleeding after abortion was 10 (2-22) days. Side effects included nausea, vomiting 19 (19\%) patients received antiemetic drugs), and diarrhea 14 (14\%) patients from misoprostol treatment. 68 patients $(68 \%)$ required oral analgesics, 22 $(22 \%)$ required diclofenac suppositories and ten patients $(10 \%)$ required parenteral opiate analgesia.

\section{DISCUSSION}

Compared with expectant management a surgical option has a higher success rate for completing the miscarriage in women with missed or anembryonic pregnancies and usually in a shorter time period. Compared with surgical management, patient on medical treatment option feel a sense of control over their management plan the need of both a general anaesthetic and an invasive procedure with their associated risks are avoided. ${ }^{5}$ Surgical evacuation of early fetal demise used to be carried out to preempt complications arising from retained products of conception.This necessitates anesthesia, surgery and operating theatre resources. ${ }^{6}$ Demetroulis et al showed that a single dose of misoprostol $800 \mu \mathrm{g}$ administered vaginally was successful in $82.5 \%$ of women with early pregnancy failure, which included women with incomplete miscarriage, missed miscarriage and anembryonic pregnancy. ${ }^{7}$ Vaginal administration of misoprostol has been shown to be more effective in comparison with the oral route as regards medical management of miscarriage and first trimester termination of pregnancy. ${ }^{8}$ Vaginal administrationresults in greater plasma concentrations and bio-availability of misoprostol compared with the oral route. ${ }^{9}$ Mifepristone is relatively expensive and a reasonable success rate $(>80 \%)$ can be achieved by using a combination of 200 mg mifepristone with misoprostol. Misoprostol is cheap, effective can be stored at room temperature, and is readily available. Studies using misoprostol alone for medical management of delayed miscarriage have a success rate of $13-83 \% .{ }^{10}$ Protcols using misoprostol alone may be used in clinical practice in case mifepristone is unavailable. It has been shown that for termination of early pregnancy a single dose of $200 \mathrm{mg}$ mifepristone is as effective as $600 \mathrm{mg}$, when used in combination with a prostaglandin analogue. ${ }^{11}$

Probably due to a change in progesterone receptor sensitivity a higher dose of mifepristone may be required for medical treatment of miscarriage. Combination of mifepristone and misoprostol, had an efficacy of $97.5 \%$ in medical termination of pregnancy up to 9 weeks. ${ }^{12}$ More recently the feasibility of medical abortion has been shown at gestations between 9 and 13 weeks to have an efficacy of $95 \% .{ }^{13}$ The lower failure rate of the medical regime in asymptomaticpatients compared with symptomatic patients and medical management of early non-viable pregnancy has a much lower efficacy, probably attributable to low progesterone concentrations following fetal demise. The commonest side effects experienced by patients are gastro-intestinal symptoms. The option of medical management of early pregnancy failure is effective and has significant implications for patient satisfaction, and contributes to economic utilization of resources.

\section{CONCLUSION}

Medical treatment with $200 \mathrm{mg}$ of oral mifepristone in combination with 800,400 and $400 \mu \mathrm{g}$ of vaginal misoprostol given sequentially at 3 hour intervals is an effective and safe alternative to surgical and expectant management of early fetal demise. The avoidance of surgery and associated risks, is more economical, increases patient treatment options and patients can opt for indivisual based preferences thus resulting in patient empowerment and higher satisfaction levels.

Funding: No funding sources

Conflict of interest: None declared

Ethical approval: The study was approved by the Institutional Ethics Committee

\section{REFERENCES}

1. Hemminki, E. Treatment of miscarriage: current practice and rationale. Obstet Gynecol. 1998;179:397-8.

2. Hughes J, Ryan M, Hinshaw K, Henshaw R, Rispin $\mathrm{R}$, Templeton $\mathrm{A}$, et al. The costs of treating 
miscarriage: a comparison of medical and surgical management. Br J Obstet Gynaecol. 1996;103:121721.

3. Jurkovic D, Ross JA, Nicolaides KH. Expectant management of missed miscarriage. Br. J. Obstet Gynaecol. 1998;105:670-1.

4. Creinin MD, Moyer R, Guido R. Misoprostol for medical evacuation of early pregnancy failure. Obstet Gynecol. 1997;89:768-72.

5. Outcome of expectant management of spontaneous first trimester miscarriage: observational study BMJ. 2002;324:873.

6. Chung TK, Cheung LP, Lau WC, Haines CJ, Chang AM. Spontaneous abortion: a medical approach to management. AusT N.Z. J Obstet Gynaecol. 1994;34:432-6.

7. Demetroulis C1, Saridogan E, Kunde D, Naftalin AA. A prospective randomized control trial comparing medical and surgical treatment for early pregnancy failure. Hum Reprod. 2001;16:365-9.

8. el-Refaey H, Rajasekar D, Abdalla M, Calder L, Templeton A. Induction of abortion with Mifepristone (RU 486) and oral or vaginal misoprostol. N Engl J Med. 1995;332:983-7.
9. Zieman M, Fong SK, Benowitz NL, Banskter D, Darney PD. Absorption kinetics of misoprostol with oral or vaginal administration. Obstet Gynecol. 1997;90:88-92.

10. Herabutya Y, O-Prasertsawat P. Misoprostol in the management of missed abortion. Int $\mathbf{J}$ Gynecol Obstet. 51997;6:263-6.

11. WHO Task Force. WHO task force on postovulatory methods of fertility regulation. Termination of pregnancy with reduced doses of mifepristone. Br Med J. 1993;307:532-7.

12. El-Refaey H, Templeton A. Early induction of abortion by a combination of mifepristone and misoprostol administered by the vaginal route. Contraception, 1994;49:111-4.

13. Ashok PW, Penney GC, Flett GM, Templeton A. An effective regimen for early medical abortion: a report of 2000 consecutive cases. Hum Reprod. 1998; 13:2962-5.

Cite this article as: Dhillon AS, Dhillon KK.

Combination of mifepristone and misopristol in early fetal demise. Int J Reprod Contracept Obstet Gynecol 2018;7:2235-8. 